\title{
Modeling Defense Acquisition Strategy
}

\author{
Venelin Georgiev *
}

\section{Introduction}

Defense acquisition policy is one of the most important aspects of defense policy, and requires an efficient and effective strategy for implementation. As a universal method, modeling provides an opportunity for many different approaches to defense acquisition strategies to be developed and analyzed in order to select the best or most appropriate method, depending on a nation's current economic conditions. Variables that can be included in modeling the process of defense acquisition strategy include specific defense acquisition instrumental policies and their parameters; typical strategies currently in use in different defense acquisition domains; and strategic management tools, such as the strategic card (SC) and the balanced scorecard (BSC). In the end, the options for defense acquisition strategy that are developed through modeling are assessed based on the extent to which they appear likely to develop the set of desired military capabilities and implement the defense missions and tasks that have been set forth in the nation's defense policy, and remain in line with the level of ambition, budget resource restrictions, and level of associated risk.

\section{Defining Defense Acquisition}

The specialized literature offers a variety of definitions of the term "defense acquisition." The extent to which these definitions are different or similar depends on the point of view from which defense acquisition is considered and the topic being examined. If we try to summarize most of the existing definitions in a systematic way, we will arrive at two main types of definitions, which differ primarily in the scope or context of definition. In a broader context, defense acquisition could be defined as a process of defense products' life cycle management from the moment requirements are defined, through research and development, manufacturing or purchasing, use in operations, exploitation and maintenance, to disposal. In a more restricted context, defense acquisition is related to the process of acquiring defense products - whether by producing or purchasing them - in order to generate defense capabilities that are appropriate to the defense missions and level of ambition set forth in a nation's defense policy. In both contexts, defense acquisition plays an essential role in achieving the goals set forth in a larger defense policy, since it is intrinsically related to the development of defense capabilities, which are basis of the armed forces' missions and task implementation in the national, regional, and global contexts. In this article, defense policy is

Venelin Georgiev is an associate professor at the Center for Security and Defense Management (CSDM) in the Institute for Information and Communication Technologies at the Bulgarian Academy of Sciences. His areas of interest include defense resource management, defense acquisition and risk management, innovations and investment management, controlling, and economic analysis. 
presented as a policy that encompasses both ends and means, and under which the desired ends drive the creation of adequate means (or forces). ${ }^{1}$ From such a point of view, the mission of defense acquisition is to deliver and maintain part of these means: armaments, equipment, infrastructure, etc.

Defense acquisition is also of particular importance because it is a process that often consumes an enormous amount of public resources, which are invested in defense programs and projects that often carry a high level of associated risk. Because of size of the investment required, defense acquisition management demands high levels of transparency and accountability in order to minimize corruption, which can cause a failure to deliver promised results. Defense acquisition projects, as a rule, are extremely costly, which is an argument for the importance of effective and efficient management of these projects. In an environment of extremely restricted or limited resources, the question of effective defense acquisition management becomes increasingly pressing and decisive. The specific characteristics of defense acquisition and its management, mentioned above, determine the significant role to be played by defense acquisition strategy as an instrument in helping reach common goals in the area of defense management. These needs place ever-higher demands on the instruments and tools (such as modeling) that are used in developing a sound defense acquisition strategy.

Defense acquisition strategy is an instrumental strategy, a unique tool that is used to reach the desired effects in the area of defense acquisition; at the same time, it is used to offer a long-term plan for the development of defense acquisition that is in line with changes in the defense system and the security environment. Defense acquisition strategy is a capabilities-based solution that is grounded in a thorough economic evaluation of alternatives. It could be defined as offering a "helicopter view" of the path toward progress in defense. ${ }^{2}$ The main purpose of defense acquisition strategy is to propose rational models and approaches for the realization of the defense acquisition policy, as well as to achieve the overall defense policy. Defense acquisition strategy should provide decision makers with necessary top-level information for balancing risk against resource constraints and performance needs.

Defense acquisition strategy could also be defined as an instrument for defense management and implementation of defense policy in the context of suitable management concepts. In Figure 1, defense acquisition policy is presented as an element of the overall national defense policy. This approach guarantees that the goals of defense acquisition are synchronized with the nation's broader goals for the defense and security sector. The practical realization of defense acquisition policy becomes possible in an area that is delineated by the parameters of the defense acquisition management concept. On the other hand, the field of the concept is an environment in which a variety of efficient and accepted defense acquisition strategies can be applied, which in the end

1 Todor Tagarev, "The Art of Shaping Defense Policy: Scope, Components, Relationships (but no Algorithms)," Connections: The Quarterly Journal 5:1 (Spring-Summer 2006): 55-69.

2 Elizabeth Wright, "Twenty First Century Defense Acquisition: Challenges and Opportunities," Connections: The Quarterly Journal 5:1 (Spring-Summer 2006): 71-80. 


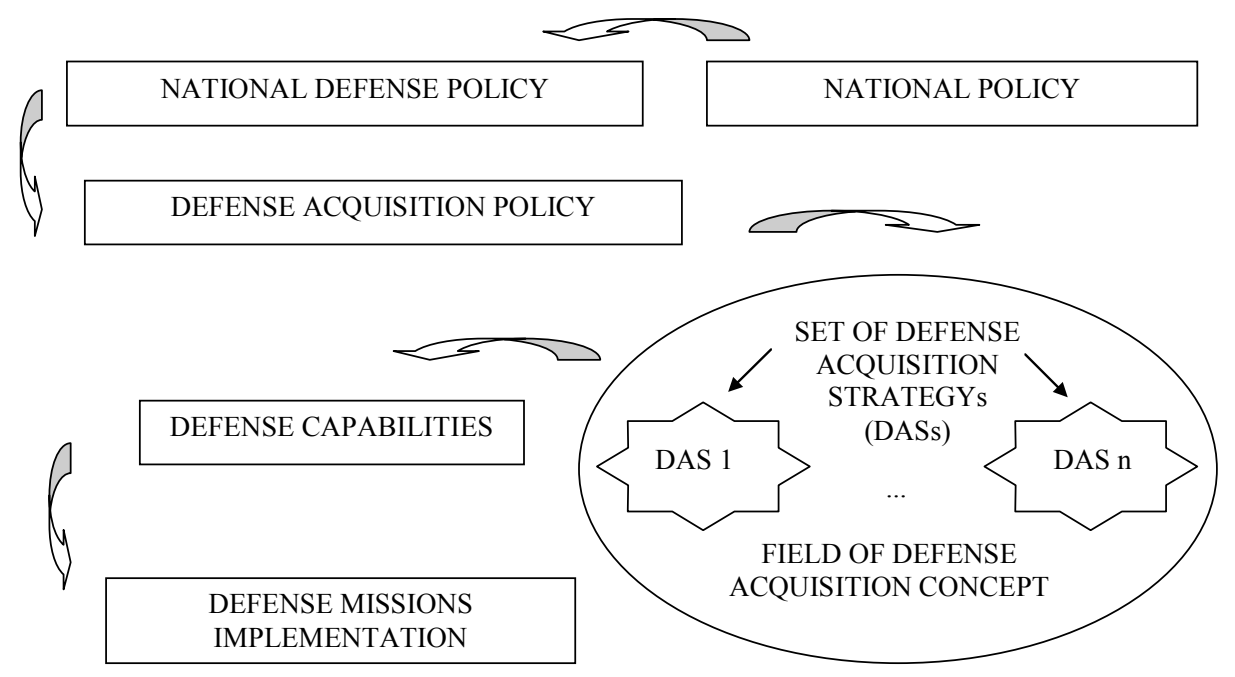

Figure 1: Role and Place of Defense Acquisition Strategy in the Transition from Defense Policy to Defense Capabilities.

can guarantee the development of the defense capabilities that are required to meet the threats posed by the security environment, accomplish prescribed defense missions, and are in line with the nation's level of ambition, resource limitations from the defense budget, and acceptable levels of organizational, technical, technological, program, and project risk.

Defense acquisition strategy development could be described as a structured decision-making process that takes into consideration all important elements of the acquisition process: sourcing, cost, logistics, innovation, and technologies. ${ }^{3}$ The capacity to generate different alternatives for defense acquisition strategy and the need to choose the most appropriate one offers the possibility to model the process of defense acquisition strategy development. Inputs to the model should include the parameters of instrumental defense acquisition policies, typical strategies for different defense acquisition domains, and applied instruments for strategy development, such as strategic cards (SC) and balanced scorecards (BSC). Sources of data and information for the model's implementation could include existing legislation, STANAGs, allied publications, etc. In summary, modeling the defense acquisition development process offers real potential to achieve enhancements in the efficiency of defense acquisition management in the context of creating defense capabilities that will guarantee the realization of the defense policy.

3 Wright, "Twenty First Century Defense Acquisition: Challenges and Opportunities." 


\section{Implementing Defense Acquisition Policy}

The successful implementation of defense acquisition policy is a vital part of national defense policy, and can make a significant contribution to reaching national goals and priorities in the defense and security area. The activities and results of defense acquisition policy have broad scope, and possess some specific characteristics. First, defense acquisition policy is aimed at the efficient life cycle management of defense products in order to develop the desired set of defense capabilities within the financial restrictions of the defense budget. Second, defense acquisition policy contributes to the implementation of the defined missions, goals, tasks, and priorities of the defense sector through effective management of modernization projects and ensuring that the necessary defense products and infrastructure elements are in place to provide for the training and participation of the armed forces in national and international exercises, operations and missions, and in domestic relief efforts in cases of natural or industrial disasters.

Defense acquisition policy contributes to a significant extent in the implementation of agreements with NATO and the EU for guaranteeing the security of the democratic community, as set forth in accepted force goals and other initiatives. In this regard, the results of defense acquisition policy implementation can be measured by the level of security and capabilities of the armed forces to participate in joint operations with forces from partner nations. Defense acquisition policy development is focused on:

- Enhancing the efficiency of defense management and generating capabilities for further improvement of the military management system

- Realizing the process of defense modernization in an efficient and effective way by implementing innovative investment projects in order to guarantee the appropriate conditions for implementing defense missions and goals

- Supporting a standard level of quality for defense products within their life cycle and optimizing processes of disposal of unnecessary armaments, machines and infrastructures

- Broadening the scope of innovative activity as an instrument for efficient defense transformation

- Implementing national and international technical and technological experience in the process of enhancement of defense capabilities.

As an instrumental defense policy, defense acquisition policy can contribute to the development of strategic paradigms in defense in the context of creating a desired set of military capabilities. It can also help ensure the efficient allocation of and balance between invested resources and received results by implementing traditional and innovative approaches in such areas as life cycle management, research and development, project management, quality management, etc.

One of the main features of defense acquisition strategy is its complex character, which provides an opportunity to implement a range of specific acquisition policies. An example of such a policy is defense product life cycle management policy, which 
can provide a rational balance between product cost and the effects that are to be achieved not only within a given stage, but over the full product life cycle. The architecture of a defense product life cycle management system has significant implications for the improvement of the quality of defense acquisition overall. Some authors emphasize the role of operational views (OVs) of acquisition products in the architecture of the life cycle management process, which can contribute to improvements in the Acquisition Management System, and even in the Force Management System. ${ }^{4}$ They divide the OVs into four levels:

- OV-1, which usually contains the high-level operational concept, reflected in a graphical description of the architecture. In some cases, it may also present some textual description.

- OV-2 is the Operational Node Connectivity Description. This view presents operational nodes within the architecture of the acquisition system together with connectivity and the information exchanges between them.

- OV-5 is the Operational Activity Model, which presents capabilities, operational activities, relationships among activities, inputs, and outputs.

- OV-6 describes operational activity, and is divided into three sub-views as follows:

o OV-6a is the operational rules model, and it identifies business rules that constrain operation

- OV-6b is the operational state transition description, which identifies business process responses to events

- OV-6c is the operational event-trace description, and it traces actions in a scenario or sequence of events.

Another example of a specific policy that can be considered under the umbrella of defense acquisition strategy is R\&D policy, which is the basis for military transformation, development, and modernization, as well as the foundation for making efficient and effective long-term decisions. Elements of this policy include innovation activities, technology development, etc. Acquisition project management policy is focused on delivering new types of equipment and defense products or modernization of existing products in a way that guarantees efficient use of scarce financial resources, embedding new technologies, and reaching the desired level of innovation. Risk management policy is one of the most important instrumental policies in defense acquisition, and without any doubt can serve as an efficient instrument for managing defense acquisition activities in order to enhance the probability of reaching the desired end state. Defense acquisition policy in the area of standardization and codification requires the ap-

4 Aleksandar Dimov, Gueorgui Stankov, and Todor Tagarev, "Using Architectural Models to Identify Opportunities for Improvement of Acquisition Management," Information and Security: An International Journal 23:2 (2009): 188-203; available at http://infosec.procon.bg/ v23_2/Dimov_Stankov_Tagarev.pdf. 
plication of complex and systematic approaches within the framework of the defense product life cycle in order to achieve initially determined standards related to national and international norms and regulations. Defense industrial policy can also make a specific contribution to implementing defense acquisition policy. The main goal here is supporting active cooperation among national firms with respective international partners. New elements of this instrumental policy are relations with the European Defense Agency (EDA) and the creation of appropriate conditions for the integration of a nation's defense industrial capacity into the international defense market.

The technology for modeling the defense acquisition strategy development process should provide opportunities for creating products that are related to the missions, goals, and tasks of defense acquisition, and that also guarantee the appropriate environment for their practical realization as measured by created military capabilities. The mission of defense acquisition could be defined as ensuring a significant contribution to the enhancement of the armed forces' military capabilities by efficient allocation of defense resources, investments in modern and innovative armaments, and effective management of their life cycle. Practical realization of this mission is related to several key strategic goals:

- Integrating defense acquisition into the larger process of defense transformation

- Improving the effectiveness of the defense acquisition system as a tool for generating rational management decisions and their implementation environment

- Strengthening and developing the role and place of the defense acquisition system in the overall management process by improving its interaction with other management systems

- Improving the process for managing the life cycle of defense products by applying proven, widely accepted approaches and methods to maintain and enhance the capabilities of the forces

- Developing and expanding the armed forces modernization process as a factor in their transformation and constituting an effective source of new defense capabilities

- Optimizing policy and instruments for the implementation of compensatory (offset) agreements, forms of public-private partnerships, private finance initiatives, and other innovative approaches to the management of defense resources provided in the interests of defense acquisition in order to achieve the highest value for consumers and society as a whole

- Improving processes for managing the quality of defense products, ensuring the best use of research results and control measurements in acquisition practices, successfully managing the risk of acquisition activities and projects as effective tools for construction, and maintaining and developing the planned defense capabilities 
- $\quad$ Promoting the role of science, research and innovation, and defense-industrial policy as a means of establishing the skills and tools for effective and efficient cooperation with NATO and the European Union member states and partners.

\section{Defense Acquisition Concept}

The defense acquisition concept could be described as a domain for applying different appropriate defense acquisition strategies that will guarantee the implementation of defense policy goals and priorities. The role of the concept is to define the frame, parameters, rules, procedures, and practices for the formulation and realization of the defense acquisition goals. One feature should be taken into account: the concept is not restricted to applying only one strategy. In addition, the concept creates conditions under which many different and appropriate strategies can be applied in order to implement managers' decisions. Examples of defense acquisition management concepts would include life cycle management, portfolio management, and net present value for the management of investments in the area of defense acquisition.

\section{Life Cycle Management}

The idea underlying the first concept mentioned above is that if the defense products' life cycle is separated into smaller parts or stages, they will be easier to understand and manage. From a structural point of view, the process of defense products life cycle management includes three levels: life cycle phases or stages, groups of processes, and individual processes. It is possible to start any group of processes with the included individual processes step-by-step, or simultaneously at any time and any stage within the defense product life cycle. This concept has one more important advantage: the same concept is applied in all member states of NATO and the EU, which ensures mutual understanding and cooperation.

\section{Portfolio Management}

Defense acquisition is a domain of many investment projects involved in the modernization of the armed forces. That fact means that defense establishments are owners of a broad portfolio of projects, and they should manage this portfolio in the best possible way. These arguments have proved the importance of including the portfolio management concept within defense acquisition strategy. Through the use of portfolio management, two key groups of tasks could be solved in the area of defense acquisition. The first involves the development and optimization of the defense acquisition investment portfolio in a way that will guarantee the efficient and effective implementation of defense missions and tasks. The second group of tasks relates to assessing the level of efficiency, effectiveness, and acquisition risk management for all defense acquisition investment projects.

\section{Net Present Value}

The net present value (NPV) concept is based on the assessments of discounted inflows, outflows, benefits, and effects, estimated not just for one year but for the entire 
economic life of the examined alternatives. A basic rule here is to accept and start only those defense acquisition projects that have a positive assessment of their net present value. All projects with negative net present value should be rejected.

Because there are many concepts that could be applied in defense acquisition management, the question of how to choose the best one and integrate it into the defense acquisition strategy is not just a question of science but one of art. This gives an advantage to well prepared managers in the area of defense acquisition and, on the other hand, can reveal instances of bad management, inefficient decisions, and lack of professional skills in defense acquisition management.

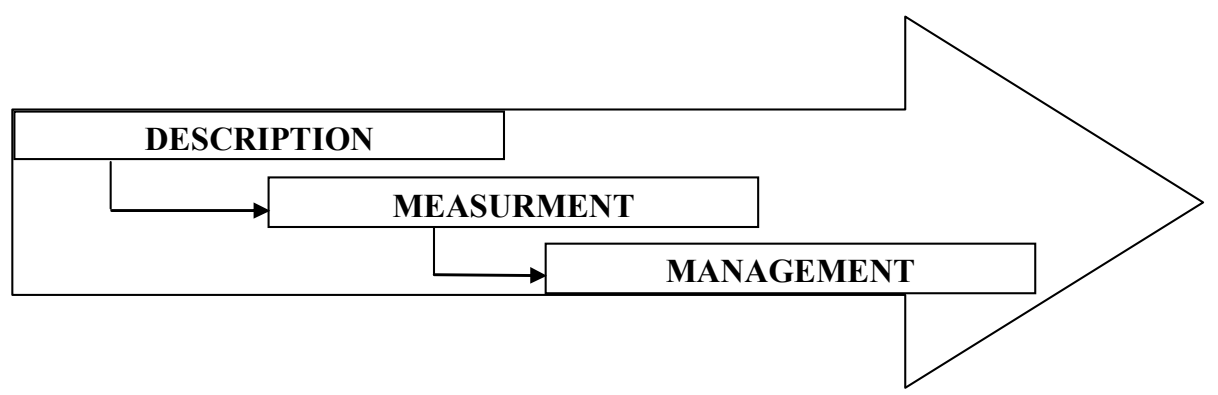

Figure 2: An Integrated Approach to Modeling Defense Acquisition Strategy.

\section{Modeling the Process}

For all of the specific areas of defense acquisition mentioned above, there are examples of typical acquisition strategies, which can be classified as follows. When we think about the more narrow aspect of defense acquisition that includes just purchasing defense products, the typical acquisition strategies are delivering new defense products related to domains with more rapid tempos of technological development (for example, information technology) and repairing and modernizing existing items that belong to domains with slower rates of change of technologies (e.g., platform construction or infrastructure). If we consider how active the defense establishments are in their implementation of defense acquisitions missions and tasks, these typical defense acquisition strategies could be divided into two categories: aggressive or offensive, and passive or defensive. The aggressive ones are related to broader innovative activity in many areas: R\&D projects, licenses, "know-how," patents, cooperation with partners, etc. The passive defense acquisition strategies are more focused on adapting the current situation in defense acquisition to changes in the external environment (e.g., in technological, technical, and knowledge areas). One of the most important parameters for defense acquisition strategy is the place (or position) that is desired from a technological point of view. Here the typical acquisition strategies are technological leader, second (follower) after the technological leader, and outsider. At a given time, the armed forces could need a different acquisition project portfolio if they were to choose one or an- 
FALL 2010

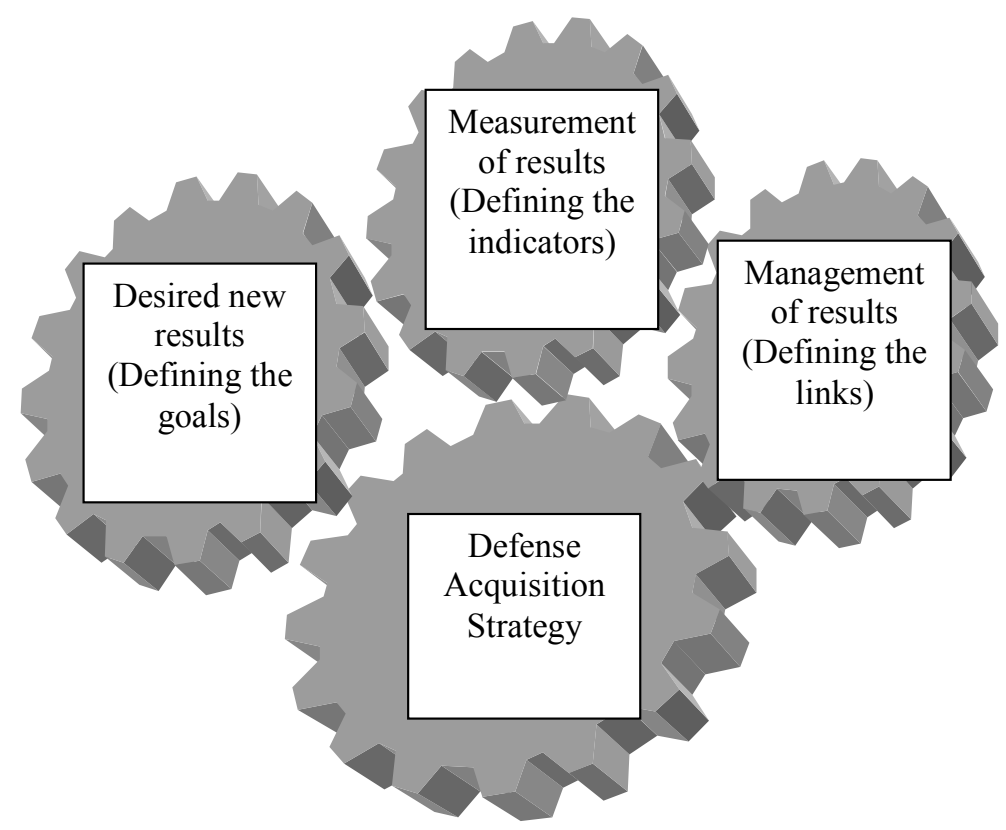

Figure 3: A Mechanism for Applying an Integrated Approach in Modeling Defense Acquisition Strategy.

other typical acquisition strategy. Based on the decision that is made about the desired technological position, the armed forces could be:

- A technological leader that can start production or exploitation of nextgeneration equipment or armaments

- A second-stage adopter after the leader that can not independently begin development of next-generation technological items, but rather follows the leader in a respective domain at a distance smaller than one technological generation

- An outsider that remains at a distance of more than one technological generation from the leader.

In modeling the defense acquisition strategy process, a broad list of external and internal factors should be simultaneously considered, and innovative practices, theoretical concepts, and benchmarks should be applied. As was mentioned, defense acquisition strategy is a tool that needs to be developed and improved in line with changes in the status of contractors and the environment for implementing the strategy. The rational approach to updating the acquisition strategy is a defensive approach, one that preserves positive results (i.e., the sustainability of the policy for defense acquisition and the systems for its implementation) and simultaneously creates the necessary con- 


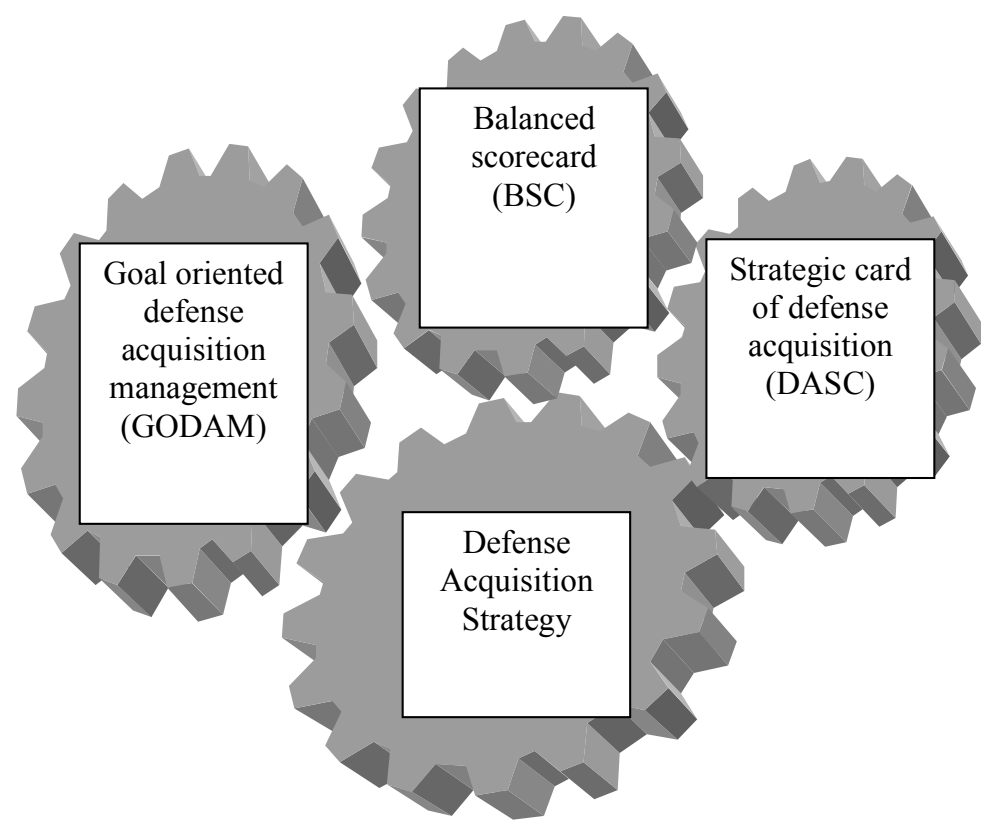

Figure 4: A Modified Mechanism for Applying an Integrated Approach in Modeling Defense Acquisition Strategy.

ditions for further development and improvement (i.e., providing variability and adaptability in defense acquisition policy).

At the heart of modeling of defense acquisition strategy is the trinity of "description $\rightarrow$ measurement $\rightarrow$ control" (see Figure 2). The reason for using these three connected processes is that, for a business activity (in this case, defense acquisition) to be measured, it should be described; and if the activity in question is going to be successfully managed, it must be able to be measured. ${ }^{5}$ The chosen approach for the development of defense acquisition strategy can be presented schematically, as shown in Figure 3. The individual units of the mechanism for applying an integrated approach in developing a strategy for defense acquisition are characterized by the following:

- Achieving qualitatively new results in the field of defense acquisition-as defined by its objectives, priorities, and tasks - is possible only if the defense organization maintains and develops results-oriented management

- Creating opportunities for the measurement of performance using the selected indicators by applying a balanced scorecard (BSC)

5 Robert D. Kaplan, The Balanced Scorecard: Translating Strategy into Action (New York: W.W. Norton, 1996). 
- Creating opportunities for the effective management of performance by applying a strategic card (SC) of defense acquisition and the definition therein of goals, objectives, actions, and causality between them.

\section{Strategic Card}

In considering the above adjustments, the mechanism for implementing an integrated approach to developing a strategy for defense acquisition (shown in Figure 3) can be modified, as shown in Figure 4. Using a strategic card (SC) as a tool for modeling the defense acquisition strategy development process provides two significant advantages. First, it enables both internal and external contractors and operators to achieve the desired level of detail and understanding of the defense acquisition strategy. Second, it allows planners to illustrate the dynamic character of the development and implementation of defense acquisition strategy.

A strategic card for defense acquisition should be developed in compliance with several important principles. The first is to consider the issue of balance between conflicting forces/principles. As an example, investments in intangible assets within the defense acquisition system to achieve long-term results often conflict with the objective of reducing the cost of achieving short-term efficiency. The second principle relates to the fact that stable value in the field of defense acquisition is created by internal processes and the development of the defense acquisition system's intangible assets. The strategic card for a defense acquisition process describes the vital activity of internal processes (strategic issues). The application of this approach allows for a defense acquisition strategy to be built on the development of complementary strategic themes. The third principle relates to the fact that the value of the intangible assets within a defense acquisition system depends on how well they relate to the strategic mission. The process of establishing the value of intangible assets in the field of defense acquisition is characterized by the following features: ${ }^{6}$

- The value inherent in intangible assets is often of an indirect character. Intangible assets in the area of defense acquisition - such as knowledge, motivation, technology, innovation, organizational culture, etc.- rarely have a direct impact on indicators that relate to financial performance. This happens through a chain of causal relationships, which can be defined and presented by the strategic card.

- The value created by intangible assets is contextual in nature, and is determined by their compliance with a given defense acquisition strategy. The existence of differences between the quality of intangible assets for a defense acquisition system and their strategic requirements is an indicator of the expected low value generated by these intangible assets.

- The value created by intangible assets is often potential rather than actual. Investments in intangible assets in the field of defense acquisition are charac-

6 Kaplan, The Balanced Scorecard. 


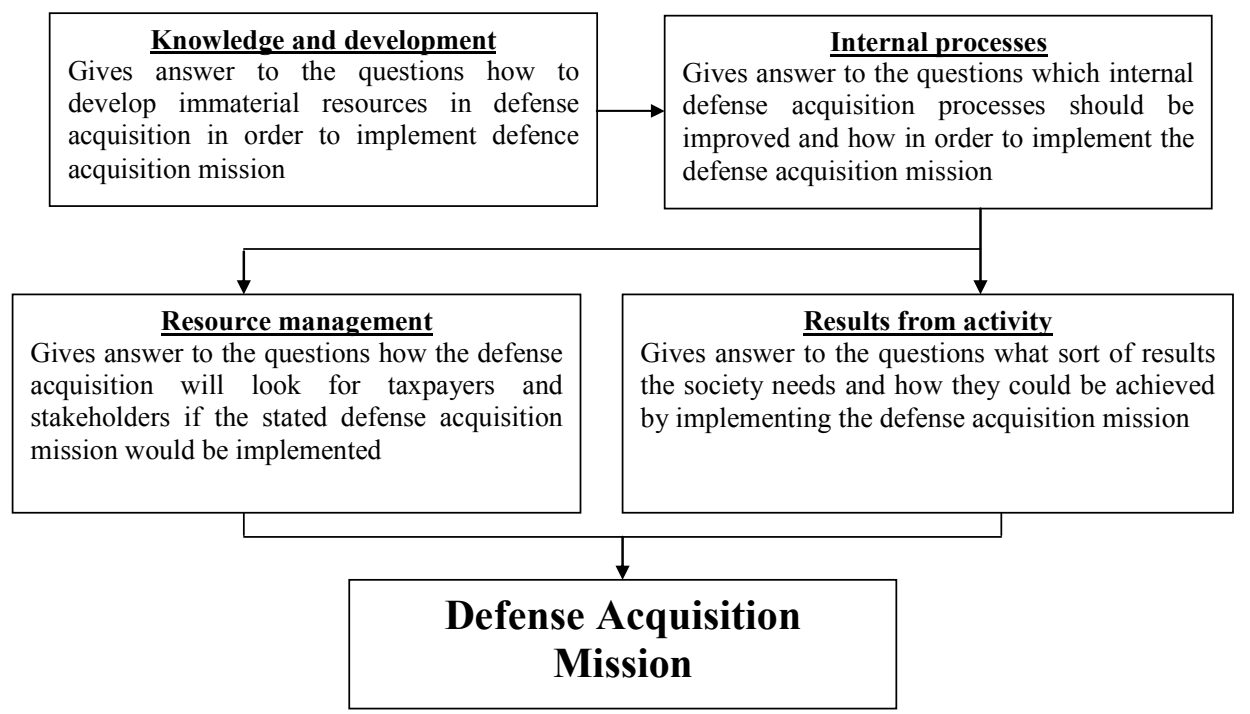

Figure 5: Perspectives to Be Used in Developing a Strategic Card for Defense Acquisition.

terized by potential rather than market value; only the internal processes of the defense acquisition system can realize this potential value.

- There is an interdependence between the various assets involved in defense acquisition, which means that the intangible assets of a given defense acquisition system can rarely create value on their own, because they do not possess the ability to do so in isolation within the defense strategy. Sustainable value is created when the intangible and tangible assets of a defense acquisition system are well synchronized.

In the strategic card, the objectives in the field of defense acquisition are modeled in four perspectives (see Figure 5 above).

The "knowledge and development" perspective provides an answer to the question of how to invest in staff, innovation, technology, infrastructure, and organizational culture to transform a defense acquisition strategy into reality. The "internal processes" dimension can give answers to the question of what processes should be implemented or improved upon in order to implement the strategy for defense acquisition. The "resource management" perspective addresses the extent to which the management of the available resources for defense acquisition is performed correctly and in accordance with overall strategic goals. The "results from activity" dimension responds to the question of whether efforts in the field of defense acquisition have achieved the results that a nation's political leadership, strategic management processes, partners, society and citizens expect. 


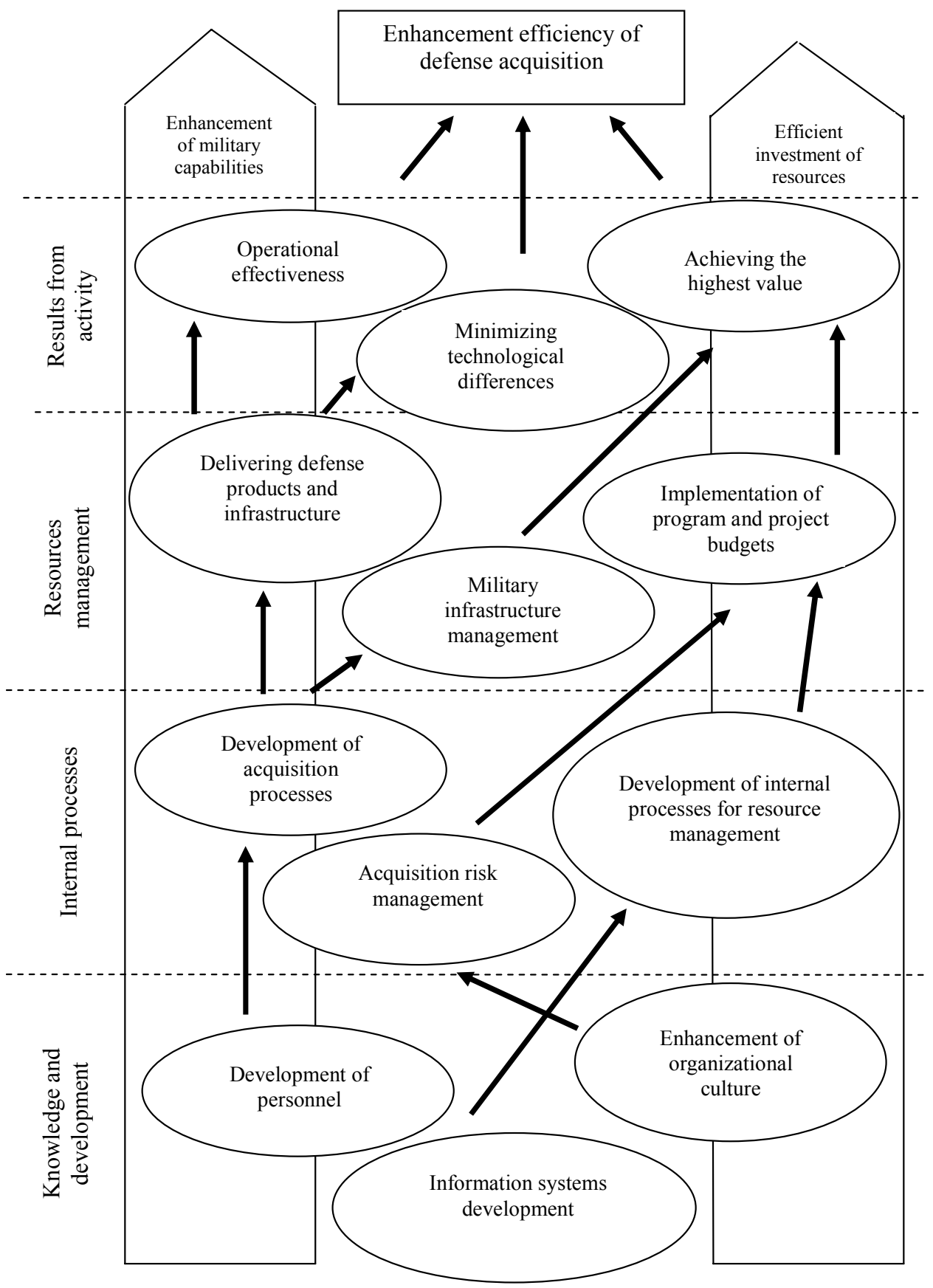

Figure 6: Model of a Strategic Card for Defense Acquisition. 
The strategic card for defense acquisition presents a visual linkage between the objectives and perspectives of a defense acquisition strategy. It describes the logic of the strategy, defining the vital and creative value of the internal processes and the intangible assets that are necessary to achieve the acquisition goals and objectives. ${ }^{7} \mathrm{~A}$ model of a strategic card for defense acquisition is presented on Figure 6.

How the strategic map of the defense acquisition process actually works can be described using an example that analyzes a procedure for extending the operation period of defense products. The development of an innovative technological procedure is based on the knowledge and experience of the experts in defense, on the development of information systems, and on improvements in the organizational culture (all of which fall under the "knowledge and development" dimension on the strategic card). The application of the procedure is made possible through the existence of internal processes for managing acquisition activities and the associated risk (falling under the "internal processes" dimension).

The result of applying the procedure is the effective management of defense products within the acquisition (investment) programs and projects (under the "resource management" perspective). The benefits derived from the procedure consist in providing the forces with defense products with an extended service period that can be used in carrying out military missions, goals, and objectives (the "results from activity" dimension). Other examples could also be used to illustrate how to apply a strategic card in the development or updating of a defense acquisition strategy.

\section{Balanced Scorecard}

Another tool for modeling the defense acquisition strategy development process is a balanced system of performance indicators — or a balanced scorecard (BSC)—which is designed to apply a systematic approach to determining indicators and measuring performance along the four dimensions described in the strategic card for defense acquisition. It transforms the objectives from the strategic card into specific tasks, whose implementation is measured by indicators for which targets are set and that those who are actually doing the work can more easily measure. Moreover, the use of indicators to measure the extent to which the acquisition tasks have been implemented allows contractors to define their role and contribution to the implementation of the defense acquisition strategy, which increases their adherence to the objectives and adds to their level of performance.

Developing a balanced scorecard for defense acquisition offers the following advantages:

- The use of performance indicators enables actors to measure the realized degree of suitability of various acquisition processes to achieving strategic objectives (i.e., the effectiveness of acquisition processes can be measured).

7 Robert D. Kaplan, The Strategy-Focused Organization: How Balanced Scorecard Companies Thrive in the New Business Environment (New York: W.W. Norton, 2001). 
- Performance indicators enable the systematic measurement of all the results in the field of defense acquisition.

- The target values of various performance indicators can be balanced (i.e., the indicators that are used to measure complex goals to be achieved have attainable, realistic values).

\section{Integration}

The effectiveness of modeling in developing defense acquisition strategies largely depends on the successful integration and synchronization of the strategic card (SC) and balanced scorecard (BSC). The successful implementation of a defense acquisition strategy is a function of the clear definition and supported launch of strategic initiatives in the form of investment programs and projects (see Figure 7).

Figure 8 presents an example of a matrix model for integrating the strategic card and balanced scorecard of performance indicators in defense acquisition. The perspectives and objectives defined in the strategic card are supplemented by the corresponding performance indicators and targets that make up the contents of a balanced scorecard. Quantitative estimates for the target values of performance indicators could be derived from accepted standards, norms, technical documents, or they can be defined by developers, depending on the level of ambition of the defense acquisition policy.

\begin{tabular}{|l|l|l|l|l|l|}
\hline \multicolumn{2}{|c|}{ Strategic card (SC) } & Balanced scorecard (BSC) & \multicolumn{2}{c|}{ Action plan } \\
\hline Perspectives & Goals & Indicators & Targets & $\begin{array}{c}\text { Programs } \\
\text { and } \\
\text { projects }\end{array}$ & Budget \\
\hline $\begin{array}{l}\text { 1. Results from } \\
\text { activity }\end{array}$ & & & & & \\
\hline $\begin{array}{l}\text { 2. Resource } \\
\text { management }\end{array}$ & & & & & \\
\hline $\begin{array}{l}\text { 3. Internal } \\
\text { processes }\end{array}$ & & & & & \\
\hline $\begin{array}{l}\text { 4. Knowledge } \\
\text { and } \\
\text { development }\end{array}$ & & & & & \\
\hline
\end{tabular}

Figure 7: Model of the Relationship between Defense Acquisition Strategy Instruments. 


\begin{tabular}{|c|l|l|l|}
\hline \multicolumn{2}{|c|}{ STRATEGIC CARD } & \multicolumn{1}{c|}{ BALANCED SCORECARD } \\
\hline $\begin{array}{c}\text { Perspectives } \\
\text { 1. Results from } \\
\text { activity }\end{array}$ & $\begin{array}{l}\text { In the area of suppliers: } \\
\text { Providing contractors } \\
\text { with actual price } \\
\text { information for new } \\
\text { defense products }\end{array}$ & $\begin{array}{l}\text { Indicators } \\
\text { Ensuring that } \\
\text { contractors are } \\
\text { provided with actual } \\
\text { price information for } \\
\text { new defense products }\end{array}$ & $\begin{array}{l}\text { Providing } \\
\text { answers on 90 } \\
\text { percent of } \\
\text { questions }\end{array}$ \\
\hline & $\begin{array}{l}\text { Ensuring the timely } \\
\text { provision of desired } \\
\text { information to } \\
\text { contractors }\end{array}$ & $\begin{array}{l}\text { Providing } \\
\text { answers to } \\
\text { contractor } \\
\text { questions within } \\
\text { three days }\end{array}$ \\
\hline & $\begin{array}{l}\text { Enhancement of the } \\
\text { effectiveness of } \\
\text { procedures of defense } \\
\text { product delivery based } \\
\text { on acquisition } \\
\text { programs and plans }\end{array}$ & $\begin{array}{l}\text { Percentage of } \\
\text { successfully } \\
\text { implemented } \\
\text { acquisition programs } \\
\text { and projects }\end{array}$ & $\begin{array}{l}\text { Successful } \\
\text { completion of } \\
80 \text { percent of } \\
\text { defense } \\
\text { acquisition } \\
\text { programs and } \\
\text { projects }\end{array}$ \\
\hline
\end{tabular}

Figure 8: Model of a Matrix for the Integration of the Strategic Card and Balanced Scorecard in the Area of Defense Acquisition.

\section{Conclusion}

The description and enumeration of the elements of a defense acquisition strategy as well as the identification of functional and meaningful alternatives provide the ability to develop a variety of defense acquisition strategies. This requires the assessment and selection of a preferred option for a defense acquisition strategy, as well as supporting the chosen approach through the use of modeling. The huge financial resources required in defense acquisition and the associated high levels of risk are factors that make mandatory the application of modeling processes in developing defense acquisition strategy. In other words, in the field of defense acquisition and management, rational managers will prefer not to use the unreliable "trial-and-error" method, and will instead choose to apply modeling methods suitable to the defense acquisition strategy development process in order to optimize the management decisions and obtained results. The application of such an approach guarantees that efficient defense acquisition management decisions will be made, in both good financial times and bad. 


\section{Bibliography}

Dimov, Aleksandar, Gueorgui Stankov, and Todor Tagarev. "Using Architectural Models to Identify Opportunities for Improvement of Acquisition Management." Information \& Security: An International Journal 23, no. 2 (2009): 188-203.

Kaplan, Robert D.. The Strategy-Focused Organization: How Balanced Scorecard Companies Thrive in the New Business Environment. New York: W.W. Norton, 2001.

Kaplan, Robert S., and David P. Norton. "The Balanced Scorecard: Translating Strategy into Action ." Harvard Business School Press (1996).

Tagarev, Todor. "The Art of Shaping Defense Policy: Scope, Components, Relationships (but no Algorithms)." Connections: The Quarterly Journal 5, no. 1 (2006): 15-34.

Wright, Elisabeth. "Twenty First Century Defense Acquisition: Challenges and Opportunities." Connections: The Quarterly Journal 5, no. 1 (2006): 71-80. 